\title{
Measurements of Metal Contamination, Antimicrobial and Antioxidant Activities of Five Medicinal Herbs from Azad Kashmir
}

\author{
Muhammad Riaz ${ }^{1}$, Muhammad Zahid², Muhammad Azhar Sherkheli ${ }^{3}$, \\ Muhammad Altaf ${ }^{1}$, Saima Manzoor ${ }^{1}$, Noman Abbasi ${ }^{1}$, Rehana Rashid ${ }^{4}$, \\ Muhammad Qayyum Khan ${ }^{5}$ and Saiqa Andleeb ${ }^{6}$ \\ ${ }^{1}$ Department of Chemistry, University of AJK, Muzaffarabad, Pakistan \\ ${ }^{2}$ University of Nebraska Medical Center, University of Nebraska, Omaha, NE, USA \\ ${ }^{3}$ Department of Pharmaceutical Sciences, Abbottabad University of Science and Technology \\ Havelian, KPK, Pakistan \\ ${ }^{4}$ Department of Chemistry, COMSATS Institute of Information Technology, Abbottabad, KPK, Pakistan \\ ${ }^{5}$ Department of Botany, University of AJK, Muzaffarabad, Pakistan \\ ${ }^{6}$ Department of Zoology, University of AJK, Muzaffarabad, Pakistan
}

(Received: June 10, 2018; Accepted: July 19, 2018; Published: January 17, 2019)

\begin{abstract}
We studied the metal contaminations as well as antimicrobial and antioxidant activities of five medicinal species: Berberis lyceum (Sumbal), Datura stramonium (Joz-e-masel), Semicarpous anacardium (Bhalawa), Fumaria indica (Shahtara) and Gymnema sylvestre (Gurmar) using atomic absorption spectrophotometry and agar-well diffusion method against E. coli and S. aureus and $\mathrm{ABTS}^{+\bullet}$ decolorization assay. We found that the contamination levels of $\mathrm{K}, \mathrm{Ca}, \mathrm{Mg}$, and $\mathrm{Ni}$ are above the standard permissible limits and should be monitored. B. lyceum has been found to possess highest antimicrobial activities against both strains. Besides B. lyceum, D. stramonium, S. anacardium and $F$. indica have shown promising antioxidant activities. Phytochemical investigations are required to isolate antimicrobial and antioxidant compounds from these medicinal plants.
\end{abstract}

Key words: Metal contamination, Antimicrobial, Antioxidant, Medicinal herbs.

\section{Introduction}

Drug resistance and emergence of new diseases have led to the state of emergency for the discovery of new antimicrobial agents (Rex et al., 2013). Invasive microorganisms have wicked adaptive nature which combined with extensive use of antibiotics and sluggish R \& D outcomes desperately require effective research for new drugs. Biological processes essentially require energy which comes through oxidation reactions however, imbalanced and excessive oxidative processes produce reactive oxygen species (ROS). These ROS are highly reactive species which modulate the structures and functions of critical biomacromolecules including nucleic acids, proteins and lipids etc. and hence create many biological disorders including lethal cancers, neurodegenerative, cardiovascular diseases, cataracts, diabetes, inflammations and atherosclerosis (Halliwell, 2005). Nature has unmatched metabolic engineering machinery which are proven precursors of new drugs, leads, knowledge and inspiration to combat fatal diseases. Therefore, natural products have revived critical importance for new drug discovery and development (Newman and Cragg, 2012). Medicinal plants and herbs have been used immemorial time to treat diseases since and that led to the development of traditional herbal medicinal products (THMPs) and then modern molecular drugs (Riaz et al., 2015). Medicinal plants are the factories for the nature design and synthesis of variety of

Correspondence to: Muhammad Riaz, Email: mriazm1 @ yahoo.com, Phone: (92)334 9270235. 
phytochemicals which in fact binds to the biomacromucules and modulate these disorders. These natural products are still major source for new drug discovery and development and their contribution for anticancer and antimicrobial drugs is still over 70\% (Newman and Cragg, 2012). Pakistan is naturally blessed with diverse climatic condition from Northern Himalayian, central hot region to southern moderate conditions which create and facilitate rich and diverse metabolic engineering of therapeutic natural products in its medicinal flora. Additionally, Pakistan has rich culture and knowledge of using these medicinal species to treat and prevent various ailments. Biological screening of these medicinal plants is the first starting point to the discovery of medicinal natural products from medicinal plants (Riaz et al., 2015). Industrialization has profoundly changed environments and ecosystems which increased the contaminations of many toxins including toxic metals. The heavy metals are toxic and are terribly damaging human health because: 1) these atomic species are nondegradable, 2) vacant orbitals of these metals lovingly make bonds with almost all biomacromolecules which unwantedly alter their structures and functions to generate lethal diseases. These toxic metals $(\mathrm{Cd}, \mathrm{Pb}, \mathrm{As}, \mathrm{Hg})$ create some of the worst diseases for example, neurological disorders and cancersand they also damage tissues and organs (Nessa and Khan, 2015; Järup, 2003). Pakistan is one of the major global producer, user and exporter of these medicinal species and being a developing country its systems requires many improvements, standardizations, regulations. Therefore, in this study we undertook the estimation of metal contamination, antimicrobial and antioxidant properties of five medicinal plants from Pakistan. We selected five medicinal plants namely, B. lyceum, $D$. stramonium, $S$. anacardium, $F$. indica and $G$. sylvestre. The metal contents in these plants were estimated using atomic absorption spectroscopy whereas, antimicrobial and antioxidant activities were determined through agar well diffusion method and $\mathrm{ABTS}^{+\bullet}$ radical scavenging assay, respectively.

\section{Material and Methods}

Plant material collection: These selected five medicinal plants, bark of Berberis lyceum(MRBL), seeds of Datura stramonium (MRDS), seeds of Semicarpous anacardium (MRSA), stems of Fumaria indica (MRFI) and leaves and stems of Gymnema sylvestre (MRGS), were purchased in dried form local herbal shops of Muzaffarabad city of Azad Kashmir, Pakistan. Both local names and botanical names were confirmed and then checked by Botany of the University of AJK, Muzaffarabad, Pakistan.

Preparation of plant extracts: Specific parts of each plant were ground to a fine powder for extraction. Conventional solvent extraction technique was used to prepare the methanolic extract of each plant. 75 grams of fine powders of each plant material was soaked in $500 \mathrm{ml}$ of methanol $(\mathrm{MeOH})$ at room temperature for about 15 days in air tight conical flasks. After that, each fraction was filtered and filtrates were dried on rotary evaporator under reduced pressure and controlled temperature. Most of the obtained residues were gummy paste and were further dried and stored in air tight Eppendorf tubes. Each extract was given a specific code and then used for analyzing their antimicrobial and antioxidant properties, whereas, 1 gram of dry powder of each plant was subjected to acid digestion for the estimation of their metal contamination.

Sample preparation and determination of antimicrobial activities: The antimicrobial activities was performed by using agar-well diffusion method (Rios et al., 1988). The dried methanolic extract (20 $\mathrm{mg}$ ) of each plant was dissolved in $1 \mathrm{ml}$ of methanol in 5 separate air tight Eppendorf tubes to prevent the contamination and were kept for four days to ensure solubility.

Test microorganisms: Two human bacterial pathogens Escherichia coli, (gram -ive, rod shaped) and Staphylococcus aureus (gram +ive) were obtained from Department of Zoology, University of AJK, Muzaffarabad, Pakistan and were used for the determination of antimicrobial activities. 
Agar-well diffusion method: Nutrient agar and nutrient broth media were used for bacterial culture. Microorganisms were activated by inoculating a loop full of strain in $50 \mathrm{ml}$ (for each pathogen) of nutrient broth medium and incubated at $37^{\circ} \mathrm{C}$ on a rotary shaker for $24 \mathrm{hrs}$. The culture was mixed with freshly prepared nutrient agar medium (NAM) at $45^{\circ} \mathrm{C}$ and was poured into the sterilized Petri- dishes. All petridishes were kept at room temperature in laminar flow for solidification. In each plate, three wells of $5 \mathrm{~mm}$ diameter were made using a $1 \mathrm{ml}$ of sterilized micropipette tip and sterilized needle was used for the removal of agar plug. $30 \mu \mathrm{l}$ of each extract (20 $\mathrm{mg}$ dried extract $/ 1 \mathrm{ml}$ and $0.6 \mathrm{mg} / 30 \mu \mathrm{l}$ of each sample solution) was used to check activities and control solvent samples were placed in each well and kept at $37^{\circ} \mathrm{C}$ for $24-48 \mathrm{hrs}$. Methanol was also used as a negative control and streptomycin was used as a positive control antibiotic drug. Microbial growth was determined by measuring the diameter of zone of inhibition after 24-48 hrs in millimeters. Diameter of the clear zones (if greater than $5 \mathrm{~mm}$ ) around each well was measured with the help of a scale.

Sample preparation for antioxidant activities: 10 $\mathrm{mg}$ of dried methanolic extract of each plant was dissolved in $2 \mathrm{ml}$ of methanol in 5 separate test tubes. ABTS radical cation $\left(\mathrm{ABTS}^{+\bullet}\right)$ decolorization assay was used to evaluate antioxidant properties of the methanolic extracts of selected five medicinal plants (Re et al., 1999).

ABTS $^{+}$decolorization assay for antioxidant activities: $\mathrm{ABTS}^{+\bullet}$ stock solution was prepared by reacting potassium per sulphate and $\mathrm{ABTS}^{+\bullet}(33.75$ $\mathrm{mg}$ potassium persulphate $+64.8 \mathrm{mg}$ of $\mathrm{ABTS}+100$ $\mathrm{ml}$ of distilled water) and allowed to stand in dark for $\sim 16 \mathrm{hrs}$ to generate ABTS free radical cation. Absorbance of the standard solutions was recorded at $734 \mathrm{~nm}\left(\right.$ Ao $\left._{\text {Control }}\right)$ after diluting with water up to respective volume. For percent scavenging activity (\% RSC) of each extract, $2 \mathrm{ml}$ of $\mathrm{ABTS}^{+\bullet}$ and $20 \mu \mathrm{l}$ of each extract $(10 \mathrm{mg}$ dried extract in $2 \mathrm{ml}$ in $\mathrm{MeOH}$ ) were mixed and then followed by the addition of $0.5 \mathrm{ml}$ distilled water to make the volume of reaction mixture up to $2.5 \mathrm{ml}+20 \mu \mathrm{l}$ while blank contained $2.5 \mathrm{ml}$ of distilled water and $20 \mu \mathrm{l}$ of extract solutions only. The absorbance (Ai) of each sample was measured at $734 \mathrm{~nm}$. All measurements were taken in triplicates and ascorbic acid was used as a positive control. The percentage radical scavenging activities (\% RSC) were calculated using the formula:

$$
\% \mathrm{RSC}=\left[\left(\mathrm{Ao}_{\text {Control }}-\mathrm{Ai}_{\text {Sample }}\right)\right] / \mathrm{Ao}_{\text {Control }} \mathrm{X} 100
$$

Where $\mathrm{A}_{\text {control }}$ is the absorbance of ascorbic acid and $\mathrm{A}_{\text {test }}$ is absorbance of the test sample.

Activity was given by only $0.1 \mathrm{mg}$ of each extract, as only $20 \mu \mathrm{l}$ of each extract $(10 \mathrm{mg}$ dried extract $/ 2 \mathrm{ml}$ and $0.1 \mathrm{mg} / 20 \mu \mathrm{l}$ of $\mathrm{MeOH}$ ) was used to check absorbance as of each sample solution.

Acid digestion, sample preparation for the analysis of metal contamination: One gram of dry powder of each plant was taken in a pyrex glass beaker and $6 \mathrm{ml}$ of concentrated nitric acid $\left(\mathrm{HNO}_{3}\right)$ and hydrogen peroxide $\left(\mathrm{H}_{2} \mathrm{O}_{2}\right)$ were added (in $2: 1$ V/V). Mixture was stirred slowly at room temperature. The glass beaker was covered with a petri dish and heated at $70^{\circ} \mathrm{C}$ for three hours. Small volumes of $\mathrm{HNO}_{3}$ and $\mathrm{H}_{2} \mathrm{O}_{2}$ were added to this mixture along with continuous heating at $80^{\circ} \mathrm{C}$ till a clear solution was obtained. The excess of acid was evaporated and a semi dry mass was obtained. The semi dry mass was solubilized in $10 \mathrm{ml} \mathrm{HNO}_{3}(0.1$ M) and was transferred to a $50 \mathrm{ml}$ volumetric flask. Total volume of solution was made $50 \mathrm{ml}$ with the addition of doubly distilled water (Tuzen, 2003).

Specification of AAS: Operating parameters of atomic absorption spectrophotometer (AAS) Analyst $^{700}$ was used in the analysis of trace metals using respective Wavelength in the range of 190 $900 \mathrm{~nm}$, diffraction grating: 1800 lines/mm blazed at $236 \mathrm{~nm}$ and $597 \mathrm{~nm}$, grating area: $64 \times 72 \mathrm{~mm}$, reciprocal linear dispersion: $1.6 \mathrm{~nm} / \mathrm{mm}$ (nominal), Focal length: $267 \mathrm{~mm}$, spectral bandwidths: 0.2, 0.7 and $2.0 \mathrm{~nm}$, dual height, motorized slit drive for automatic slit selection with wide-range segmented solid-state detector. Analyst ${ }^{700}$ used winlab 32 program to automatically calculate the mean of three reading of three sample of each spice for each metal. 


\section{Results and Discussion}

Antimicrobial activities of five medicinal plants: Antibacterial activities of the methanolic extracts were assessed by the agar-well diffusion method against E. coli and S. aureus. Zones of inhibitions (ZI) for all extracts were measured in $\mathrm{mm}$, three readings were taken for each sample and mean value was calculated. Results of the sensitivity tests were expressed as (0) for no sensitivity, *(1- $5 \mathrm{~mm})$ for low sensitivity, $* *(>5-10 \mathrm{~mm})$ for moderate sensitivity and $* * *(>10-25 \mathrm{~mm})$ for high sensitivity. Only one of the methanolic extract of B. lyceum (MRBL) showed high sensitivity (>10-25 mm) of 17 and $16.66 \mathrm{~mm}$ against both microbes $E$. coli and $S$. aureus ,respectively. D. stramonium (MDRS) showed moderate sensitivity $(>5-10 \mathrm{~mm})$ of $6 \mathrm{~mm}$ against $E$. coli and low sensitivity of $1.66 \mathrm{~mm}$ against S. aureus. S. anacardium (MRSA) also showed low sensitivity of $1.33 \mathrm{~mm}$ against $E$. coli and zero against S. aureus. F. indica (MRFI) and G. sylvestre (MRGS) showed no sensitivity against both the microbes. Comparative sensitivities of mehtanolic extracts of five medicinal plants against both $E$. coli and $S$. aureusare shown in figures 1 and 2, respectively.

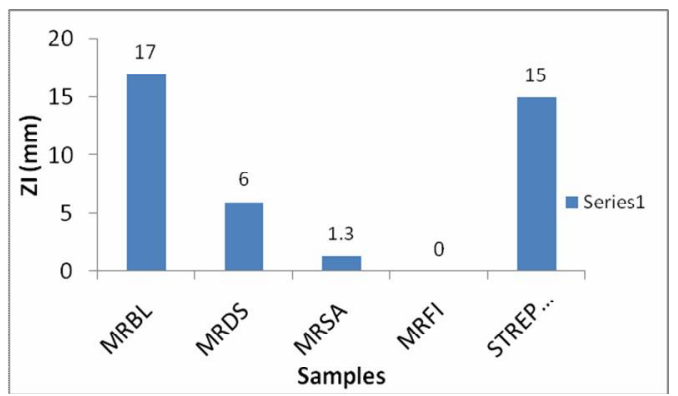

Figure 1. Zone inhibition(ZI) of methanolic extracts of five medicinal plants against $E$. coli.

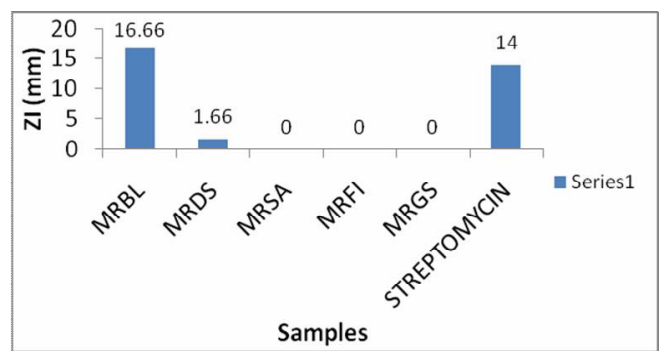

Figure 2. Zone inhibition(ZI) of methanolic extracts of five medicinal plants against $S$. aureus.
Antioxidant activities of these five medicinal plants: Antioxidant potential of the methanolic extracts of these five medicinal plants under discussion was measured by $\mathrm{ABTS}^{+}$decolorization assay. Three concordant readings were taken for each extract at $734 \mathrm{~nm}$ and mean (Ai) was calculated. Value of control (Ao) at $734 \mathrm{~nm}$ was 0.1. The percentage radical scavenging activity (\% RSC) was calculated using the formula: \% RSC $=\left[\left(\mathrm{Ao}_{\text {Control }}-\mathrm{Ai}\right.\right.$ Sample $\left.)\right] /$ $\mathrm{Ao}_{\text {Control }} \times 100 \%$. All results for these $\mathrm{MeOH}$ extracts are summarized in Table 1.

Table 1. Percentage RSC values of the methanolic extracts of five medicinal plants.

\begin{tabular}{lcc}
\hline Plant codes & $\begin{array}{c}\text { Mean }\left(\mathrm{A}_{\mathrm{i}}\right) \\
( \pm \mathrm{SD})\end{array}$ & $\begin{array}{c}\text { Percentage radical } \\
\text { scavenging activity } \\
(\% \text { RSC })\end{array}$ \\
\hline MRBL & $0.0496 \pm 0.2547$ & 51 \\
MRDS & $0.0536 \pm 1.154$ & 47 \\
MRSA & $0.030 \pm 0.155$ & 70 \\
MRFI & $0.059 \pm 0.00$ & 41 \\
MRGS & $0.095 \pm 0.00$ & 5 \\
\hline
\end{tabular}

It was observed that the $\mathrm{MeOH}$ extract of $S$. anacardium (MRSA) showed stronger $\mathrm{ABTS}^{+\bullet}$ scavenging ability with $70 \%$. Whereas, methanolic extracts of B. lyceum (MRBL), D. stramonium (MRDS) and F. indica (MRFI) showed 51\%, 47\% and $41 \%$ scavenging potential, respectively. The methanolic extract of G. sylvestre (MRGS) showed low values of $5 \%$ scavenging potential.

Metal contaminations of five medicinal plants: We analyzed the contaminations of eight metals $(\mathrm{Na}$, $\mathrm{K}, \mathrm{Ca}, \mathrm{Mg}, \mathrm{Ni}, \mathrm{Co}, \mathrm{Zn}$ and $\mathrm{Fe}$ ) in our selected five medicinal plants; [B. lyceum (Sumbal) (MRBL), D. stramonium (Joz-e-masel) (MRDS), S. anacardium (Bhalawa) (MRSA), F. indica (Shahtara) (MRFI) and G. sylvestre (Gurmar) (MRGS)] using AAS. The wavelength to measure the concentrations of each metal in extracts and the mean concentration of each metal in each extract (in $\mathrm{mg} / \mathrm{l}$ ) are given in table 2 . 
Table 2. Metal contaminations in five medicinal plants (wave length of the light used to analyze 8 metals are Na = $589.0 \mathrm{~nm}, \mathrm{~K}=766.5 \mathrm{~nm}, \mathrm{Ca}=422.7 \mathrm{~nm}, \mathrm{Mg}=285.2 \mathrm{~nm}, \mathrm{Ni}=232.0 \mathrm{~nm}, \mathrm{Co}=240.7 \mathrm{~nm}, \mathrm{Zn}=213.9 \mathrm{~nm}$, and Fe $=$ $248.3 \mathrm{~nm}$ whereas the contaminations are $\mathrm{mg} / \mathrm{l})$.

\begin{tabular}{ccccccccc}
\hline \multirow{2}{*}{ Sample } & \multicolumn{7}{c}{ Mean value } \\
& $\mathrm{Na}$ & $\mathrm{K}$ & $\mathrm{Ca}$ & $\mathrm{Mg}$ & $\mathrm{Ni}$ & $\mathrm{Co}$ & $\mathrm{Zn}$ & $\mathrm{Fe}$ \\
\hline MRBL & $6.903 \pm 0.08$ & $97.74 \pm 0.06$ & $0.904 \pm 0.3$ & $18.06 \pm 0.33$ & $5.810 \pm 0.3$ & $0.149 \pm 0.03$ & $6.138 \pm 0.19$ & $18.06 \pm 0.03$ \\
MRDS & $0.381 \pm 0.05$ & $97.74 \pm 0.07$ & $71.04 \pm 0.72$ & $22.05 \pm 0.00$ & $0.103 \pm 0.21$ & $0.014 \pm 0.008$ & $7.131 \pm 0.016$ & $17.76 \pm 0.32$ \\
MRSA & $0.265 \pm 0.07$ & $97.74 \pm 0.0$ & $85.59 \pm 0.04$ & $36.46 \pm 0.08$ & $0.358 \pm 0.03$ & $0.033 \pm 0.00$ & $7.057 \pm 0.02$ & $12.16 \pm 0.6$ \\
MRFI & $0.341 \pm 0.1$ & $97.55 \pm 0.09$ & $6.686 \pm 0.053$ & $1.612 \pm 0.03$ & $1.020 \pm 0.12$ & $0.033 \pm 0.0031$ & $9.782 \pm 0.06$ & $20.56 \pm 0.2$ \\
MRGS & $0.252 \pm 0.05$ & $96.65 \pm 0.2$ & $6.817 \pm 0.13$ & $2.396 \pm 0.21$ & $1.294 \pm 0.01$ & $0.001 \pm 0.0005$ & $6.671 \pm 0.1$ & $19.19 \pm 0.3$ \\
\hline
\end{tabular}

Studies for the metal contamination in these medicinal plants have revealed that $\mathrm{Na}, \mathrm{Zn}, \mathrm{Fe}$ and Co concentration are within standard permissible limits (SML) whereas $\mathrm{Ni}$ is above SML only in $B$. lyceum. However, $\mathrm{K}$ concentration in all these five medicinal plants has been found above the SML. Ca has been found only in B. lyceum within SML but was above SML in D. stramonium, $S$. anacardium, $F$. indica, G. sylvestre. Similarly, Mg was within SML in $F$. indica and G. sylvestre and above SML limits in B. lyceum, D. stramonium, S. anacardium.

\section{Conclusion}

On the basis of these studies, we conclude that $B$. lyceum, D. stramonium and S. anacardium should be investigated for the isolation, characterization and studies of potential antimicrobial natural products as B. lyceum has shown highest inhibition activity against both $E$. coli and $S$. aureus, whereas, $D$. stramonium has shown moderate activities against both $E$. coli and $S$. aureus and $S$. anacardium has also shown moderate inhibitory activity against $E$. coli. $B$. lyceum, D. stramonium, $S$. sanacardium and $F$. indica. They should be further investigated for the discovery of antioxidant natural products as these have shown highest antioxidant activities 71, 51, 47 and $41 \%$, respectively. We also suggest that the contaminations of $\mathrm{K}, \mathrm{Ca}, \mathrm{Mg}$, and $\mathrm{Ni}$ should be carefully monitored in these medicinal species since they are locally being purchased and used without proper medical/regulatory guidelines.

\section{Acknowledgement}

We thank Professor Dr. Raja Naseem Akhter (Professor of English) for the proof reading this manuscript.

Conflict of interest disclosure: There is no conflict of interest.

\section{References}

Goyer, R.A. 1997. Toxic and essential metal interactions. Ann. Rev. Nutr. 17, 37-50.

Halliwell, B. 2005. Free radicals and other reactive species in disease. Encyclopedia of Life Sciences, pp. 1-7

Järup, L. 2003. Hazards of heavy metal contamination. British Medi. Bull. 68, 167-182.

Nessa, F. and Khan S.A. 2015. Evaluation of free radical scavenging activity and toxic heavy metal contents of commercially available fruits of Tribulus terrestris Linn. European J. Med. Plants 9, 1-14

Newman, D.J. and Cragg G.M. 2012. Natural products as sources of new drugs over the 30 years from 1981 to 2010. J. Nat. Prod. 75, 311-335.

Re, R., N. Pellegrini, Proteggente, A., Pannala, A., Yang, M. and Rice-Evans, C. 1999. Antioxidant activity applying an improved ABTS radical cation decolorization assay Free Rad. Biol. Med. 26, 12311237. 
Rex, J.H., Eisenstein, B. I., Alder, J., Goldberger, M., Meyer, R., Dane, A., FriedlandI., Knirsch, C., Sanhai, W. R. and Tomayko, J. 2013. A comprehensive regulatory framework to address the unmet need for new antibacterial treatments. Lancet Infect, Dis. 13, 269-275.

Riaz, M., Asghar, A., Rashid, R. and Shahzad-ul-Hussan, S. 2015. Treasures hunt in old mines: Terminalia chebula-Based traditional herbal medicinal products. Nat. Prod. J. 5, 252-267.
Rios, J., Recio, M. and Villar, A. 1988. Screening methods for natural products with antimicrobial activity: a review of the literature. J. Ethnopharmacol. 23, 127149.

Tüzen, M. 2003. Determination of heavy metals in soil, mushroom and plant samples by atomic absorption spectrometry. Microchemical J. 74, 289-297. 